\title{
GIVING STUDENTS EMPLOYMENT INTERVIEW PRACTICE IN AN EFFICIENT
} MANNER

Curran, E., \& Sterritt, R. (Accepted/In press). GIVING STUDENTS EMPLOYMENT INTERVIEW PRACTICE IN AN EFFICIENT MANNER. In Unknown Host Publication International Academy of Technology, Education and Development. http://uir.ulster.ac.uk/36707/2/Acceptance_letter_INTED2017_Paper_id_55892.pdf

Link to publication record in Ulster University Research Portal

\section{Published in:}

Unknown Host Publication

\section{Publication Status:}

Accepted/In press: 20/01/2017

\section{Document Version \\ Author Accepted version}

\section{General rights}

Copyright for the publications made accessible via Ulster University's Research Portal is retained by the author(s) and / or other copyright owners and it is a condition of accessing these publications that users recognise and abide by the legal requirements associated with these rights.

\section{Take down policy}

The Research Portal is Ulster University's institutional repository that provides access to Ulster's research outputs. Every effort has been made to ensure that content in the Research Portal does not infringe any person's rights, or applicable UK laws. If you discover content in the Research Portal that you believe breaches copyright or violates any law, please contact pure-support@ulster.ac.uk. 


\title{
GIVING STUDENTS EMPLOYMENT INTERVIEW PRACTICE IN AN EFFICIENT MANNER
}

\author{
Edwin P Curran University of Ulster (UK), \\ Roy Sterritt University of Ulster (UK)
}

\begin{abstract}
Within one campus of the University of Ulster in UK, there are almost 300 students studying Computing related degrees. Each of these courses require their students to work for one year in the IT industry after completing 2 years of full time study but before enrolling for their final year. A Professional Development module is taken by all these students during their second year. This module covers a range of topics relevant to the Employment market but the first part is concerned with familiarisation with the available employment opportunities, completion of CV and Employer Application forms, handling questions at interview, assessment centre activities and practice aptitude tests. Interview practice is critical to their success. This paper will discuss previous interview practice models used before going on to describe the model used in the academic year 2015/16. Comparisons will be made between male and female students as well as students who joined the second year directly from another course completed in an affiliated college. Additional benefits have accrued to the students including observing an interview and being an interviewer. Quantitative and qualitative data extracted from student questionnaires will be presented before outlining changes to be made for 2016/17 session.
\end{abstract}

Keywords: Employability, interview practice.

\section{INTRODUCTION}

Students studying any Honours Computing degree on the Jordanstown campus of the University of Ulster are require to undertake a Professional Development module in year 2 of their course. It seeks to guide students to becoming professional in every facet of activity and covers, inter alia, topics including presenting oneself appropriately and professionally on paper, at interview as well as with peers, clients etc. Close to 300 students are enrolled on this module. Employability has been on the agenda in tertiary level education in UK for some time, with many different approaches taken to enhance the employability of undergraduate students [1]. However without good interview skills, applicants will struggle to secure their intended job. Work has been done in the authors' institution on embedding employability and published [2].

A major challenge is to provide each student with some mock interview practice which is so important as they prepare to be interviewed by companies. A relatively small proportion of the second year cohorts do have previous interview experience for mainly part time/summer jobs. The vast majority of students have had none or very little experience of handling themselves at interviews.

The second challenge is to complete this exercise in time for the first company interviews. Vacancies from companies are becoming available to year 2 students within 3 weeks of starting semester 1 .

\section{PREVIOUS APPROACHES}

\subsection{Booking using the Doodle tool}

In order to make this approach work the following required to be undertaken

Academic colleagues were asked to indicate when they would be available to conduct mock interviews. Student timetables were consulted to avoid clashes with scheduled classes. Dates and times for available interviews were published via Doodle and students could book an interview slot. Some slots were only advertised to specific course members while others were bookable by students on all courses. Interview rooms were prebooked. This process was spread over several weeks.

Colleagues were provided with a list of ten questions with the first five questions, and two out of the remaining questions to be asked of every student. All ten questions were made available to the students well in advance. The interview was to be completed by asking two questions unseen by the students. 
The first year that this pattern was adopted, a feedback sheet was completed by the interviewer and given back to the student, before beginning the next interview. On reflection, and to reduce the time needed to conduct each interview, it was decided to dispense with the written feedback. Instead students were encouraged to bring a recording device, typically their mobile phone, to record the questions asked, their responses and feedback given by the interviewer. While enough slots were provided, students did not book the early slots. When this process was rerun in the following year, schedules of interviews tended to run more on time, with each interviewer not having to spend two to three minutes at the end writing feedback. However the problem of students not booking the earlier slots still remained.

\subsubsection{Reflection}

While enough interview slots were provided, the early slots were not fully utilised, resulting in too many students trying to book in the last couple of weeks. The move to providing audio feedback which could be recorded by each student was viewed as positive but this recording option was not universally taken up. The exercise involved many academic colleagues, some of whom had unexpected clashes in their own commitments which involved last minute changes to the prearranged interviews.

\subsection{Involving Human Resource Management undergraduates}

Students on Computing courses need practice interviews before undertaking real interviews with employers, while students on the University's Human Resource Management course need practice in interviewing as part of their course. One of the authors contacted the Course Director for the latter course and discussed whether it would be possible to facilitate Human Resource Management students interviewing the Computing students. Agreement in principle was obtained with practical details having to be worked on

In order to make this approach work the following required to be undertaken. Timetables for both Human Resource Management students had to be compatible with the students on our Computing courses. The student interviewers had to be provided with job descriptions suitable for each of the Computing courses and CVs (with personal information removed) for all the interviewees. In addition, one of the authors met with the student interviewers to run through the job descriptions, explaining technical terms and answering any questions they had.

\subsubsection{Reflection}

This model ran in one academic year. It seemed to be a win - win situation with a mutual satisfying of the needs of both student groups. Interviews were held in a different part of the University ie other than the area where Computing students normally frequent. Across the 2 days of interviews, attendance was high on day 2 but patchy on day 1 . The Human Resource Management students were disappointed that more students did not turn up on day 1 , limiting their experience of interviewing. Those students who did turn up to be interviewed on day 2 were well prepared. It did not prove possible to rerun this in the following year due to illness of Module Coordinator and then subsequent course revisions within the other faculty.

\section{STUDENT CENTRED APPROACH}

Previous approaches have suffered from one or more of the following weaknesses:

(i) Making demands on academic staff time in addition to their allocated teaching load

(ii) Trying to match student availability with academic staff availability

(iii) Booking suitable rooms to match availability of students and staff

(iv) Completing the process in a clearly defined timeframe

(v) Scheduling to accommodate students who have early interviews with employers

In the 2015/16 academic year a new approach was adopted which attempted to eliminate the above weaknesses and also to provide students with an additional perspective on interviewing. 


\subsection{Preparatory work before mock interviews}

\subsubsection{Assigning students to groups}

Students on each course were allocated mostly into groups of 4 with a small number of students being assigned a group size of 3 . All groups contained students from the same course. Many of the students had already been assigned to a group of 4 for another module and these assignations were kept, with the remainder being randomly allocated.

\subsubsection{Giving students instructions regarding preparation for mock interviews}

Two weeks prior to the interviews, each student was advised as follows.

Choose a job role that they would like to be interviewed for and supply this, by email, to the other group members well in advance of the allocated interview date but not later than a specified date.

On the basis of job descriptions emailed to them, they should prepare 4 interview questions and bring these to their allocated slot.

(iii) During their allocated slot they will be interviewed ONCE but will act as interviewer for the other members of their assigned group.

\subsection{Space allocation and managing the interviews}

\subsubsection{Room booking}

In order to easily manage the process, a space was booked well in advance which was large enough to hold interviews for all groups in each course. For the 2015/16 session, a large hall (capable of seating 900 people was used for the mock interviews. Desks and chairs were distributed around the hall to avoid crowding and each table was clearly labelled with group number. Names of each group member were left secured on each table in the order of interview timing.

\subsubsection{Managing the process on the day of the interviews}

Group mock interviews were held inside a 1hour slot for each course. When students entered the hall, they sat in their groups at their allocated tables. All groups' activities were synchronised by one of the authors using the public address system.

(i) The first student to be interviewed from each group was requested to come to the middle of the hall while the remaining group members agreed who would ask which questions.

(ii) The interviewee would then return to the group. An announcement was made that interviews were now starting and timer commenced.

(iii) Eight minutes later, an announcement was made that there was 1 minute remaining, followed one minute later by a second announcement that Interview was now over.

(iv) The student just interviewed was asked to return to the centre of the hall while the interviewers completed a short feedback form. When this was completed, he/she could return to the group and act as interviewer for the remaining students.

The cycle was then repeated from (i) until all group members had a chance to be interviewed. Copies of all feedback forms were made in situ before being returned to the students at the end of the session.

\subsubsection{Student feedback to their peers}

The authors were interested in finding out what actual feedback student interviewers would provide to their student interviewees. A form was designed to be easily filled in by the interviewing panel in order to capture the following information:

(i) Identify one thing that the interviewee could improve on

(ii) Which question had the best answer given and why

(iii) Identify any mannerisms or repeated phrases used by the interviewee 
(iv)

Estimate the perceived confidence level of the interviewee on an analogue scale ranging from low to high

This forced the interviewers to provide useful (although limited) feedback and was a tangible output for each interviewee. All groups knew that copies were being made which could be traced back to the authors - this helped to ensure that useful feedback was provided.

\section{RESULTS}

The survey conducted after this mock interview was completed anonymously online by 103 students. We include below the outcomes of a number of questions that were asked in this survey.

\subsection{The location and how it could be improved}

This was the first time that a hall of this size was used for this type of activity. It was pleasing to note that $86.4 \%$ of the 103 respondents viewed the hall as either suitable or very suitable, with $7.8 \%$ viewing the location as either unsuitable or very unsuitable - see Fig. 1 below. This question was followed by a free response question asking 'How could the hall have been used better for the mock interviews?' A total of 47 responses were given and a summary is provided in Fig. 2 below.

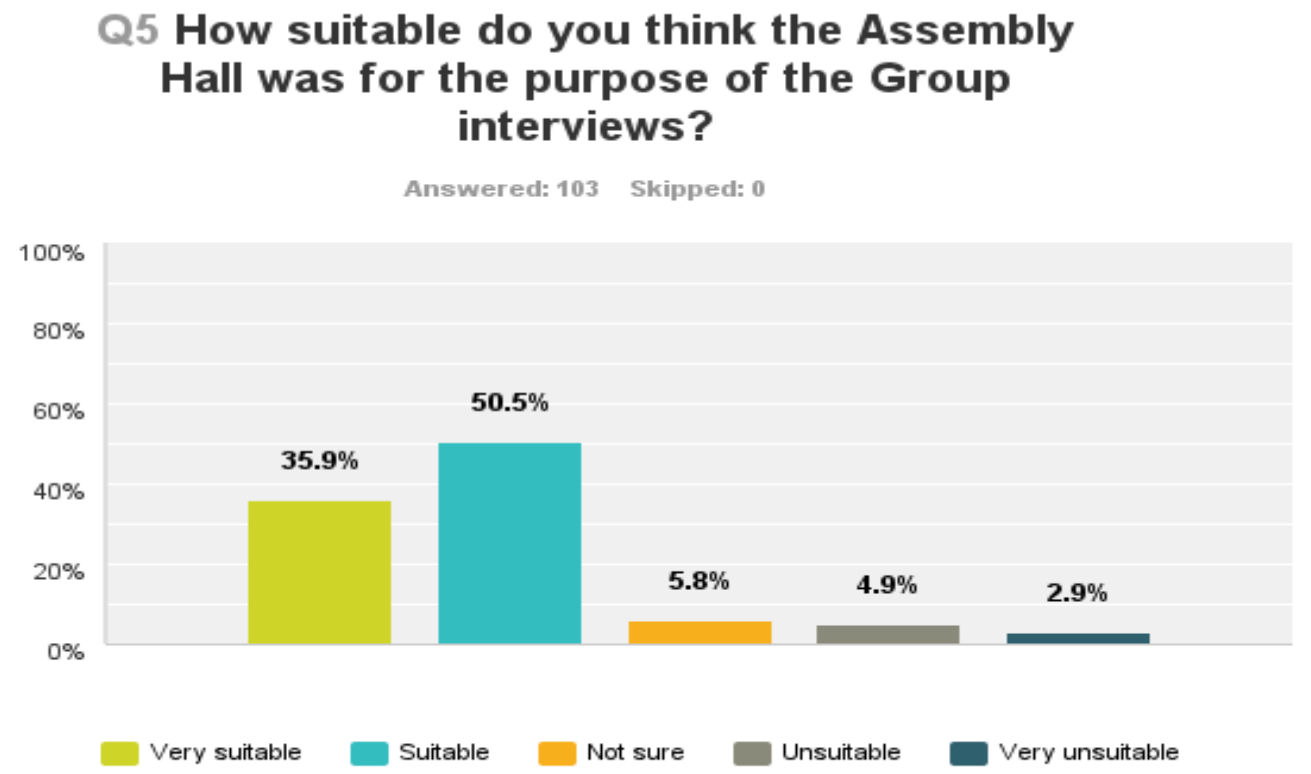

Fig. 1 Suitability of the Hall used for group interviews

\begin{tabular}{|c|c|}
\hline Improvement suggested & Number ( \%) \\
\hline More monitoring & $2(4.3)$ \\
\hline More privacy & $13(27.7)$ \\
\hline Hall layout was fine & $9(19.1)$ \\
\hline Too much space & $2(4.3)$ \\
\hline N/A & $12(25.5)$ \\
\hline $\begin{array}{c}\text { Left blank or comment not } \\
\text { relevant to question }\end{array}$ & $9(19.1)$ \\
\hline
\end{tabular}

Fig. 2 Summary of responses to question 'How could the hall have been used better for the mock interviews?'

The most popular improvement suggested (by $27.7 \%$ ) was that each group should have more privacy, with the most common suggestion being to replicate a typical interview room, rather than open plan with other groups visible. Yet almost just over 19\% did not see any problem with the layout of tables and chairs in the hall. It is fair to suggest that those 
respondents who used the N/A response were not unhappy with the hall layout. This assumption would bring to $44.6 \%$ those students who were not unhappy with the layout. Only 2 respondents (out of 47 ) wished to see a higher level of monitoring by academic staff.

\subsection{Feedback received by interviewees}

Each student who was interviewed received a copy of their feedback sheet before leaving the hall on the day of their mock interview.

The rationale behind the feedback form was that it provides a tangible output for each student with the view of helping each student deal better with real interviews as well as acting as a focus for the interviewers. The feedback form is not designed to record all of an interviewee's weaknesses and needs to be completed easily and quickly. Fig. 3 below shows the results for the respondents, showing that over $71 \%$ viewed the feedback as useful

\section{Q14 Regarding written feedback provided}

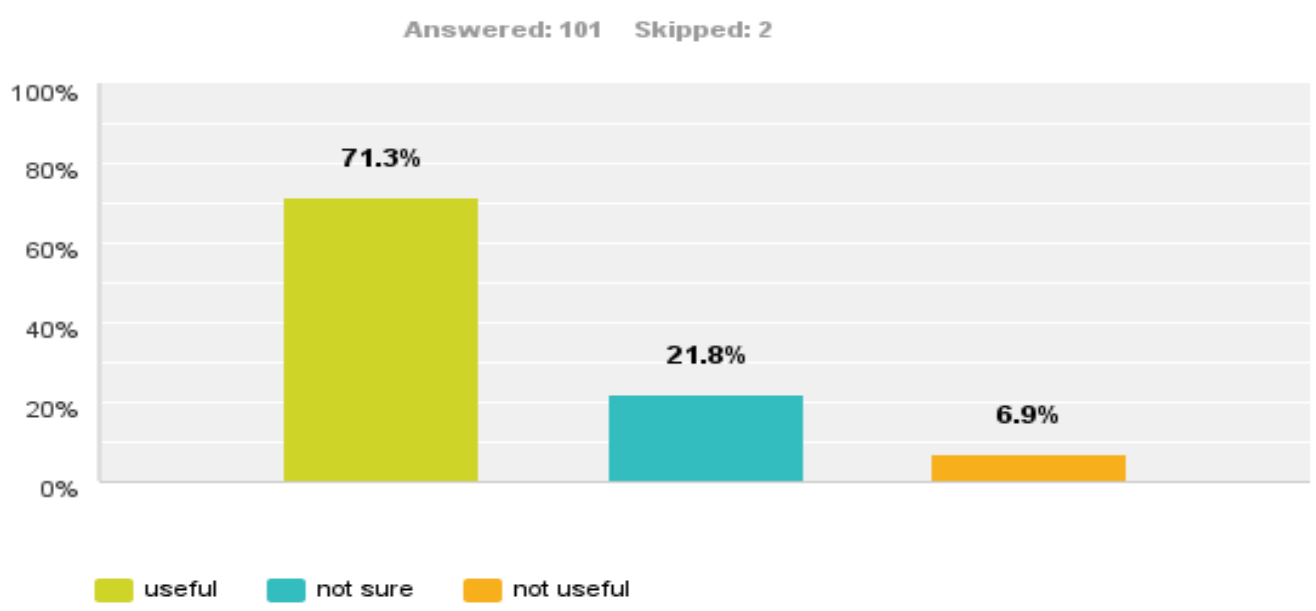

Fig. 3 Usefulness of feedback provided at the end of the interview process.

In an attempt to analyse these results further, we looked at breakdown by gender, whether or not students had joined year 2 of their course directly and whether they had applied for placements already. These results are shown in Fig 4, Fig 5 and Fig 6.

Regarding the male/female breakdown of responses (Fig. 4), it seems that almost twice as many female students as male students viewed the feedback as not useful. However when we take into account the fact that 74 of the respondents were male and 29 were female, the percentage difference is 1 student. No real difference then exists between male and female students regarding the usefulness of the feedback provided.

There were 78 respondents who came though year 1 and 25 who joined year 2 directly from another course. Fig. 5 shows the breakdown by this criterion. For both groups in excess of $67 \%$ viewed the feedback as useful but almost a quarter of students who came through year 1 were not sure if feedback was useful. In addition more of this latter group viewed the feedback as not useful (corresponding to 6 students). Overall it appears that the direct entry students viewed the written feedback more positively.

From the data shown in Fig. 6 , the feedback is rated as useful by more students who had already applied for placements compared to the others. This same group may also have had higher expectations of feedback because they realise the importance to them individually of performing as well as possible for the placements they have already applied for. Perhaps for the $7.7 \%$ who rated feedback as not useful, they may have wished to receive more detailed feedback. The other group may not have realised the importance of this yet. 


\section{Q14 Regarding written feedback provided}

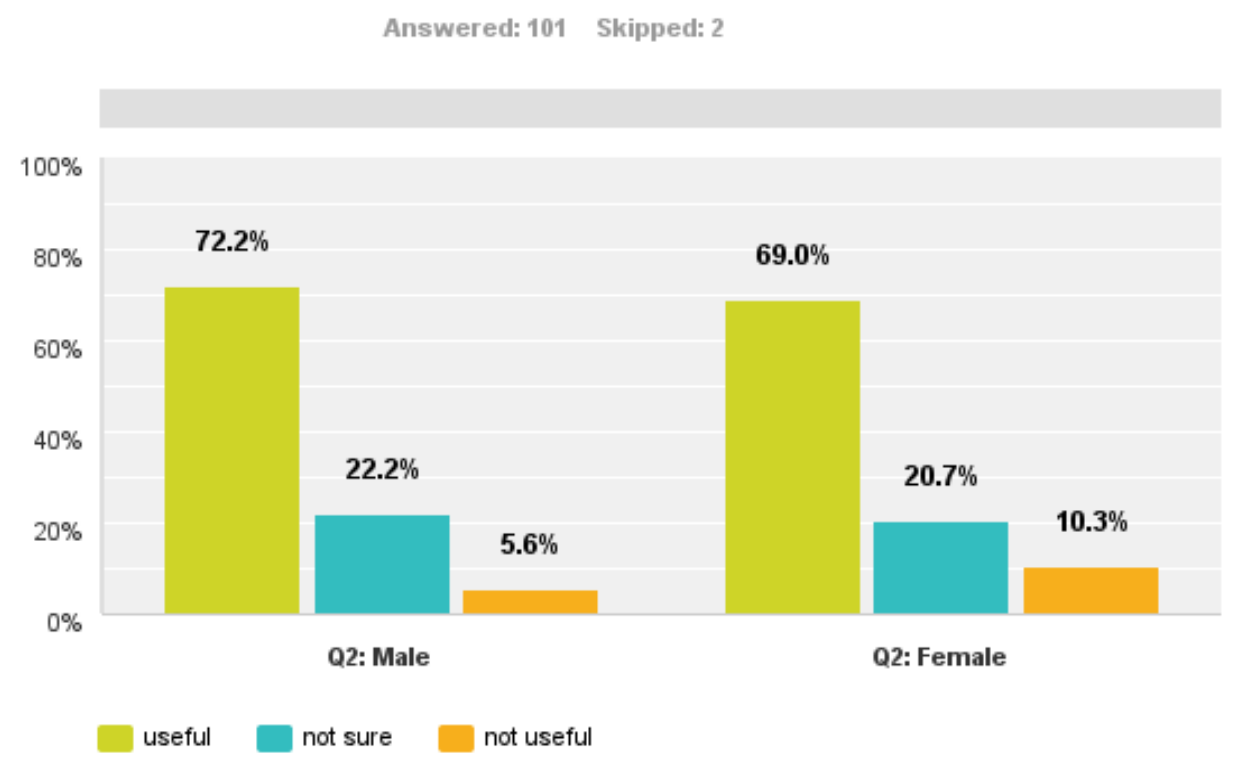

Fig. 4 Usefulness of feedback provided at the end of the interview process, broken down by gender.

\section{Q14 Regarding written feedback provided}

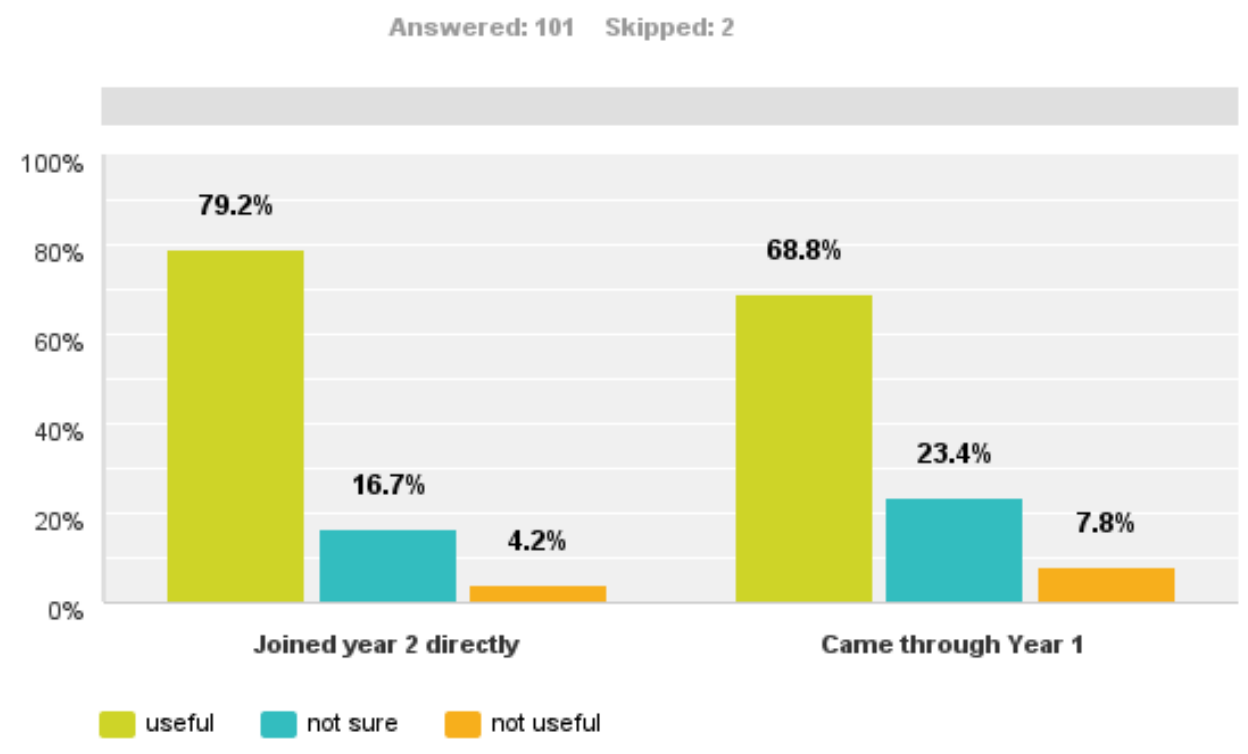

Fig. 5 Usefulness of feedback provided at the end of the interview process, broken down by year of entry 


\section{Q14 Regarding written feedback provided}

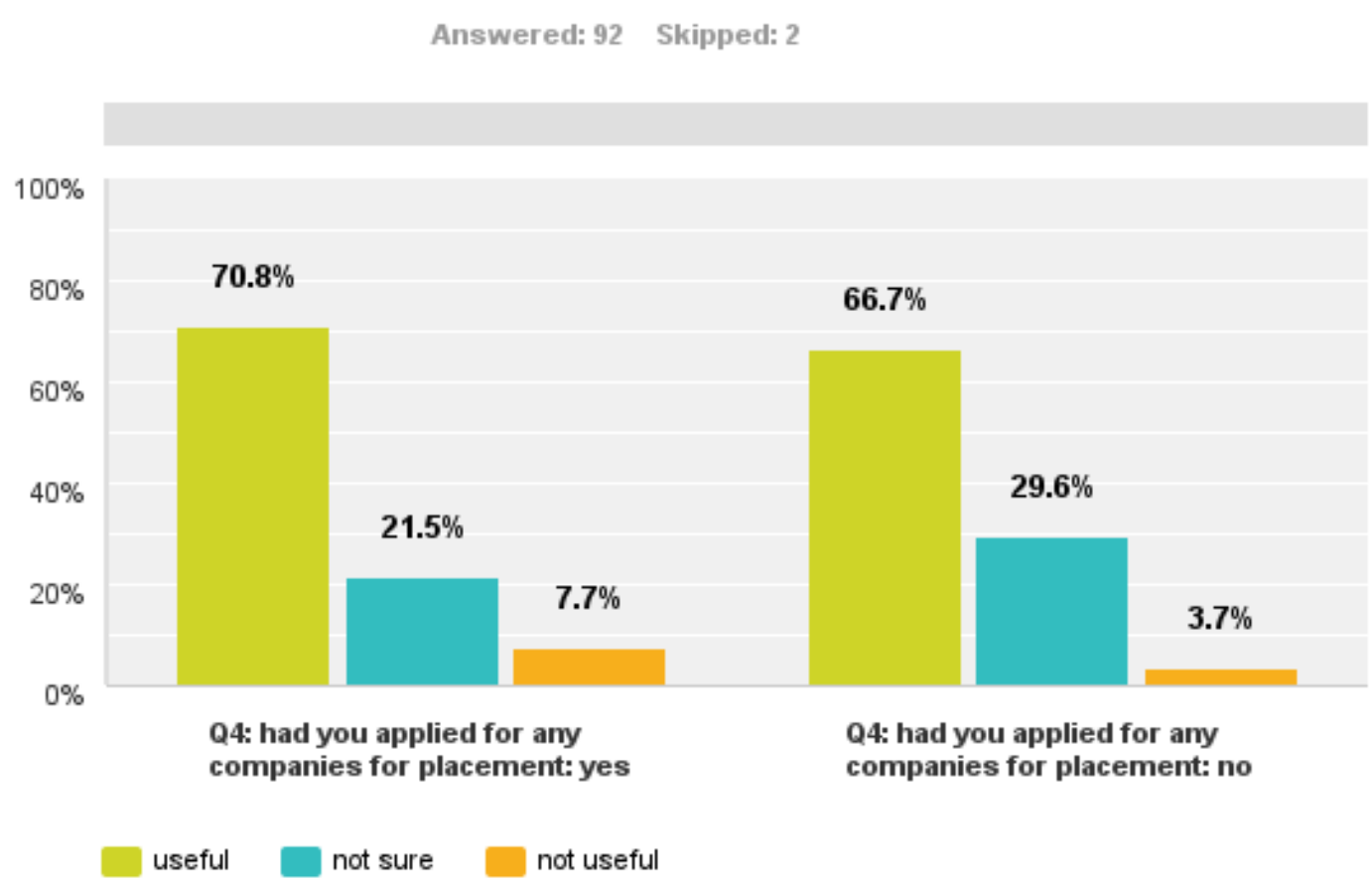

Fig. 6 Usefulness of feedback provided at the end of the interview process, comparing those who had already applied for placements and those who hadn't started applying.

\subsection{Professionalism of students participating}

The views of the participating students were sought on how professionally their peers behaved during the whole mock interview process. Results are shown in Fig. 7 below.

\section{Q9 How would you describe the attitude of your group members towards the mock interview process?}

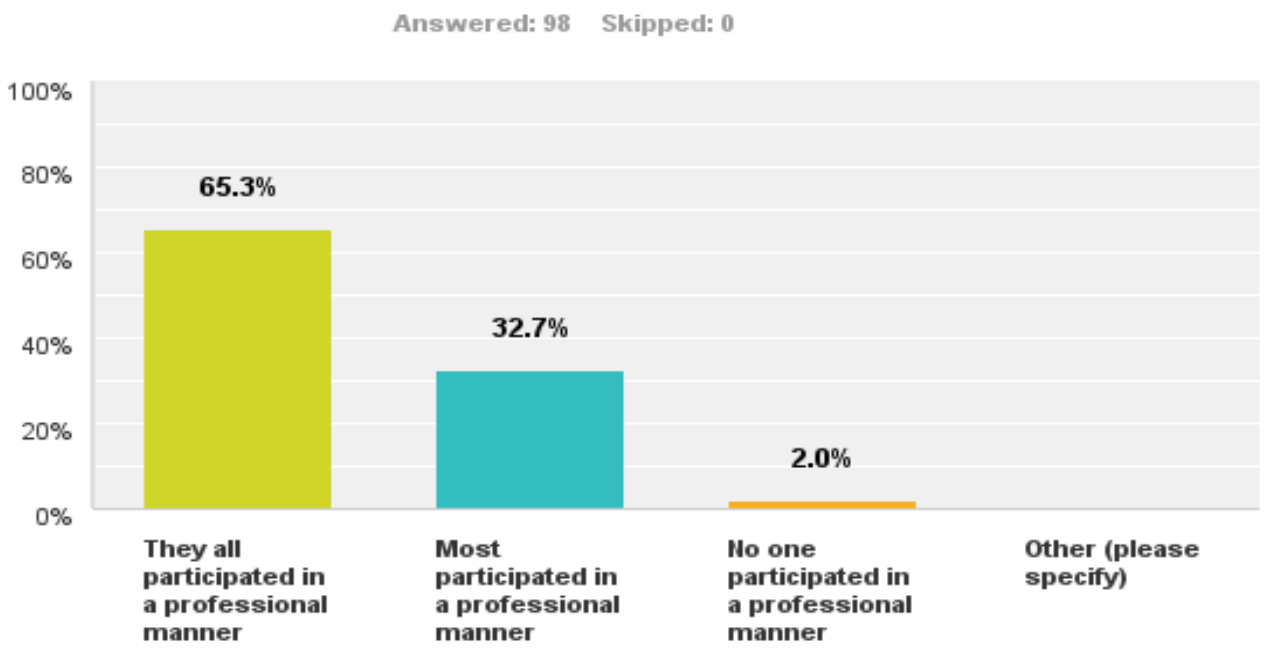

Fig. 7 Attitude of group members towards the mock interview process 


\subsection{Composition of groups}

Views were sought on options for forming the interview groups. Data is shown below in Fig 8.

\section{Q10 Regarding the students in your group, would you have preferred to}

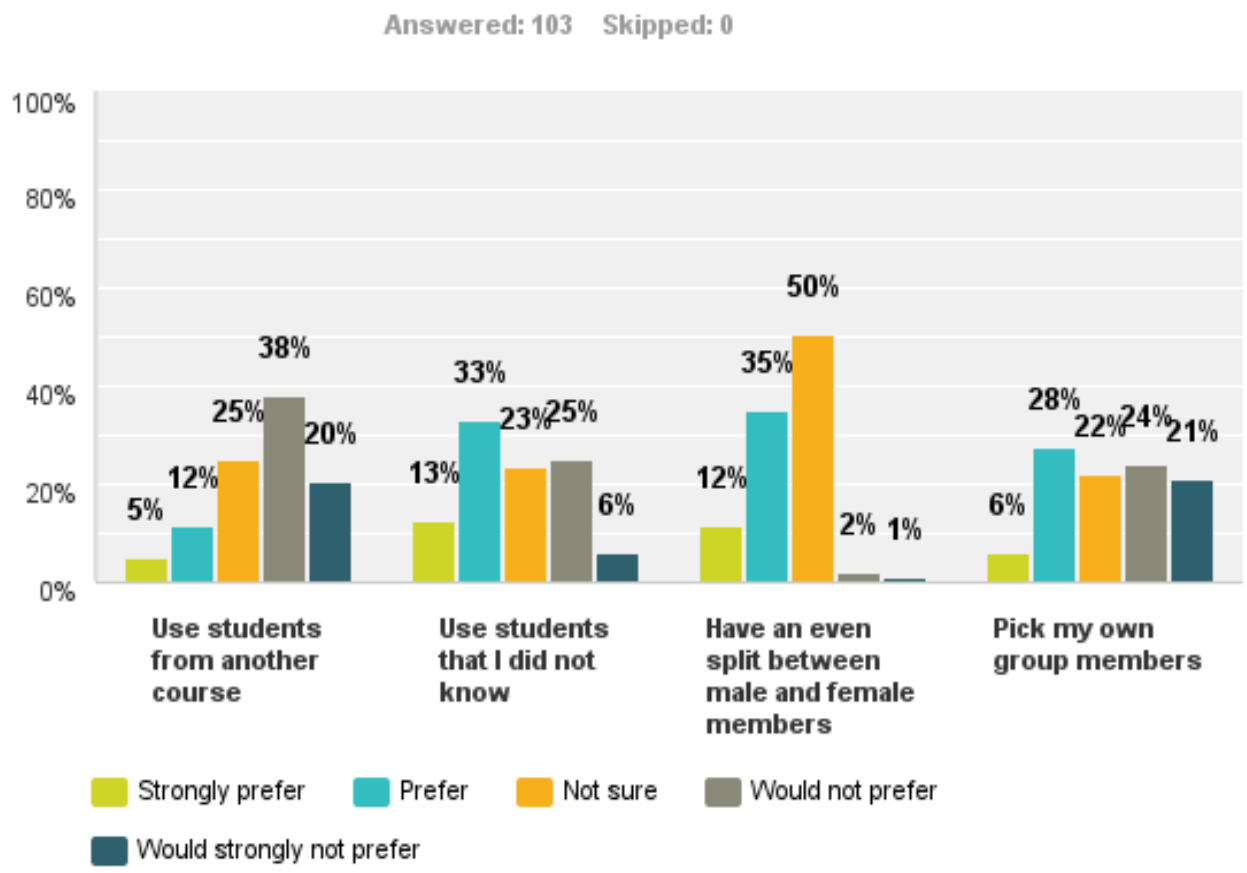

Fig. 8 Options chosen for forming groups

Regarding data presented in Fig.8, 58\% of students would either disagree or strongly disagree with involving students from other courses in the interview groups, with only $17 \%$ taking a positive view of this approach. In any case timetabling issues would usually prevent such an arrangement. The option of using students that were not known to the respondent (but on same course) meets with less resistance ( down to $31 \%$ ). Having an even split between male and female students is much more popular with only $3 \%$ disagreeing or strongly disagreeing. The final option of allowing students to pick their own group members was opposed( either disagree or strongly disagree ) by $45 \%$ of respondents.

\subsection{Interviewer experience gained}

Most, if not all of our students, would have zero experience in interviewing. This process allows them to get a different perspective on interviews ie that of an interviewer. Fig. 9 below shows the views of the respondents. These numbers are very encouraging $-87 \%$ either strongly agreed or agreed that it was useful, $93 \%$ either strongly agreed or agreed that it was good to see the body language of the interviewees and $88 \%$ either strongly agreed or agreed that it was good experience to search job descriptions for possible questions. 


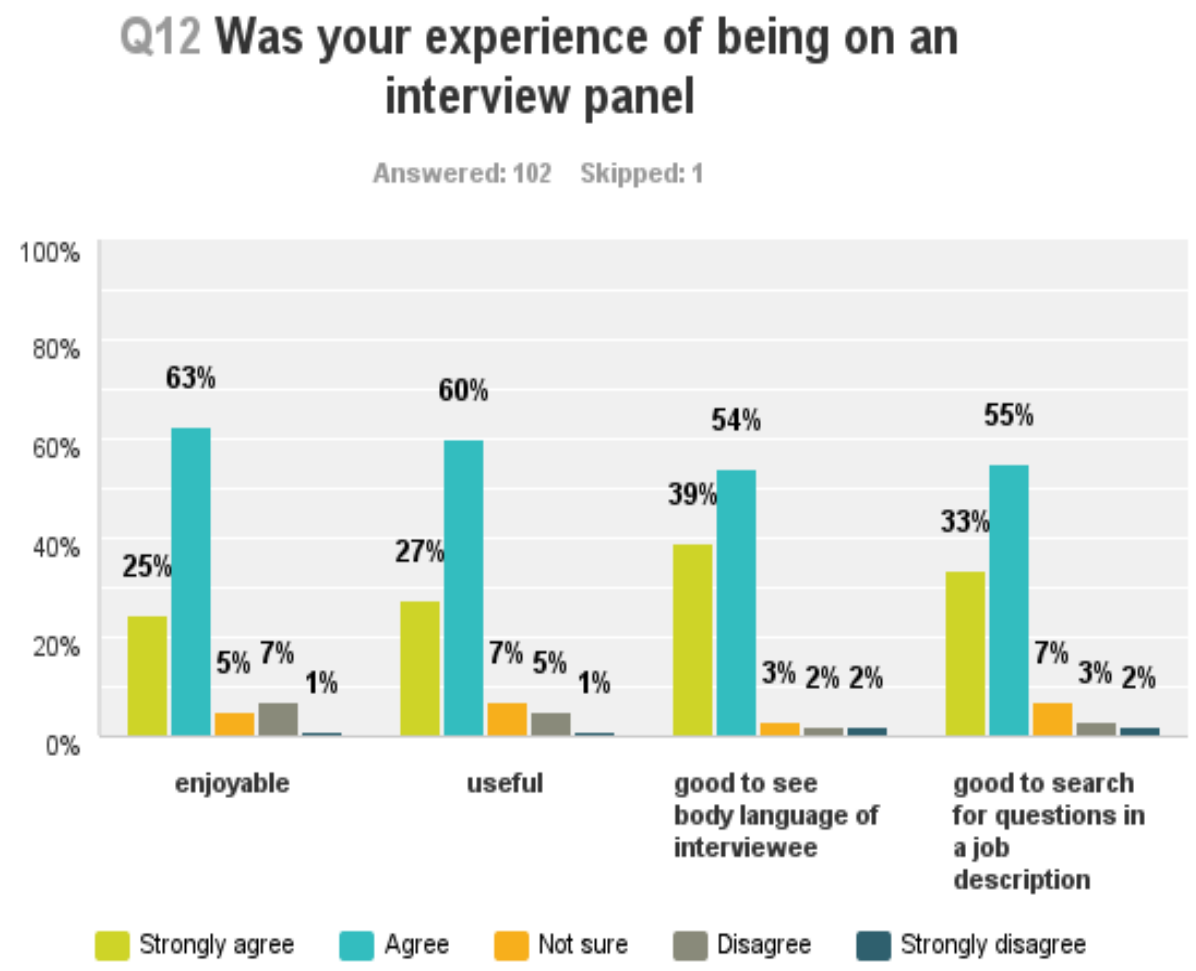

Fig. 9 Experience of being on an interview panel

\subsection{Benefits as highlighted by participants}

Students were asked to list up to 3 benefits of this group mock interview exercise. The top 4 benefits in descending order of frequency were interview experience, being an interviewer, noticing body language and receiving feedback. Two infrequently mentioned benefits, but interesting nonetheless, were 'hearing others answer questions' and 'be able to break down job descriptions for questions'

\section{THE FUTURE}

\subsection{Lessons learned}

This experience of allowing the students to take control of the exercise has been very useful as a learning exercise for the authors. It has provided a large number of students with valuable interview experience in an efficient manner. Key to the success of the approach is that

(i) Each student selects a job description that he/she is interested in and emails this to the other group members by the due date.

(ii) Each group member prepares interview questions based on the job description for each of the other group members. Some students were preparing one set of general questions for use with all the group members.

(iii) Group feedback form needs to be completed thoughtfully, with a view to helping that student improve their interview technique.

\subsection{Changes proposed for $2016 / 17$}

Distribution of the tables and chairs in the hall should stay much the same but portable partitioning should be introduced to partially screen off each of the groups. 
(ii) More visible monitoring of the interview sessions should be introduced

(iii) Groups are formed at random within courses. Timetabling constraints prevent creating groups from more than one course.

(iv) Interview duration should be slightly shortened to allow for a small increase in time to produce the feedback for each interviewee

\subsection{Conclusions}

This exercise was well worth running and it will be repeated in 2016/17, taking into account changes proposed above. For those groups where all 4 members turned up for this exercise, they will have a more realistic view of company staff interviewing perhaps 15 students for 2 roles and the importance of being able to use interesting examples which help to make them 'stand out' from the other interviewees. Awareness of interviewee's own body language is another aspect of enduring value from this exercise.

\section{ACKNOWLEDGEMENTS}

The authors would like to thank the students who took part in this pilot and in particular to those who took the time to respond to the online survey which provided the data for this paper.

\section{REFERENCES}

[1] Yorke, M., 2006. Employability in higher education: what it is, what it is not. The Higher Education Academy.

[2] Ayre, Nicola, McChesney, lan and Sterritt, Roy (2016) EMBEDDING EMPLOYABILITY IN THE CURRICULUM - THE AWARE FRAMEWORK. In: INTED 2016: 10th annual International Technology, Education and Development Conference, Valencia, Spain. http://uir.ulster.ac.uk/34037/ 